\title{
Current issues regarding the application of recombinant lactic acid bacteria to mucosal vaccine carriers
}

\author{
Keita Takahashi ${ }^{1}$ (D) Nozomi Orito ${ }^{1} \cdot$ Nagisa Tokunoh $^{1} \cdot$ Naoki Inoue $^{1}$ \\ Received: 13 February 2019 / Revised: 14 May 2019 / Accepted: 15 May 2019 / Published online: 7 June 2019 \\ (C) Springer-Verlag GmbH Germany, part of Springer Nature 2019
}

\begin{abstract}
Over the past two decades, lactic acid bacteria (LAB) have been intensively studied as potential bacterial carriers for therapeutic materials, such as vaccine antigens, to the mucosal tissues. LAB have several attractive advantages as carriers of mucosal vaccines, and the effectiveness of LAB vaccines has been demonstrated in numerous studies. Research on LAB vaccines to date has focused on whether antigen-specific immunity, particularly antibody responses, can be induced. However, with recent developments in immunology, microbiology, and vaccinology, more detailed analyses of the underlying mechanisms, especially, of the induction of cell-mediated immunity and memory cells, have been required for vaccine development and licensure. In this mini-review, we will discuss the issues, including (i) immune responses other than antibody production, (ii) persistence of LAB vaccine immunity, (iii) comparative evaluation of $\mathrm{LAB}$ vaccines with any existing or reference vaccines, (iv) strategies for increasing the effectiveness of LAB vaccines, and (iv) effects of microbiota on the efficacy of LAB vaccines. Although these issues have been rarely studied or discussed to date in relation to $\mathrm{LAB}$ vaccine research, further understanding of them is critical for the practical application of LAB vaccine systems.
\end{abstract}

Keywords Lactic acid bacteria $\cdot$ Mucosal vaccine $\cdot$ Vaccine persistency $\cdot$ Mucosal adjuvant $\cdot$ Microbiota

\section{Introduction}

Vaccines are the most cost-effective and suitable means of controlling infectious diseases. Recent vaccine development is focused on subunit vaccines consisting of components specific to pathogens instead of conventional vaccines, such as live or inactivated vaccines composed of whole pathogens. In general, subunit vaccines are thought to be safer than live or inactivated vaccines, as vaccines made of whole pathogenic microbes contain many proteins that are unnecessary for protective immunity but often carry the risk of triggering allergic or autoreactive consequences.

Mucosal routes for vaccine delivery have gained an increased interest in modern vaccinology, as mucosal vaccines can induce mucosal immunity, which is hard to induce with systemic vaccines and as mucosal surfaces represent a major

Keita Takahashi

takahashi@gifu-pu.ac.jp

Naoki Inoue

inoue@gifu-pu.ac.jp

1 Department of Microbiology and Immunology, Gifu Pharmaceutical University, 1-25-4 Daigaku Nishi, Gifu 501-1196, Japan entry site into the human body for many pathogens (Chen and Cerutti 2010). However, the mucosal administration of subunit vaccines composed of purified antigens normally induces no or only low immune responses, due to their rapid enzymatic degradation on the mucosal surface and/or the induction of mucosal tolerance (Mestecky et al. 2007). Therefore, the development of a carrier is required for the protection of vaccine antigens from the harsh mucosal environment, their delivery to the mucosa-associated lymphoid tissues, and induction of adaptive immune responses rather than tolerogenic immune responses. Currently, there are two major trends in the development of carriers for mucosal vaccines. One is based on physicochemical systems such as emulsions and liposomes (Schwendener 2014; Corthésy and Bioley 2018), and the other uses genetically modified live viruses or bacteria as vectors (da Silva et al. 2014; Lin et al. 2015).

Lactic acid bacteria (LAB) are a group of Gram-positive, non-sporulating bacteria that includes species of Lactococcus, Lactobacillus, Streptococcus, Pediococcus, Leuconostoc, Bifidobacterium, and several others. LAB is a generic term for bacteria that produce a large amount of lactic acid as the end product of sugar metabolism. From ancient times, dietary LAB have been used to ferment a wide range of raw materials, such as milk for the production of cheeses and yoghurts, as 
part of the food industry. Over the past two decades, LAB have been intensively studied as potential bacterial carriers for therapeutic materials, such as vaccine antigens, to the mucosal tissues, since LAB have several attractive advantages as a mucosal vaccine carrier, such as an excellent safety profile for human use, easy genetic manipulation, ability to be taken up into Peyer's patches, absence of endotoxins, resistance to low $\mathrm{pH}$, intrinsic adjuvanticity, and weak immunogenicity (Wyszyńska et al. 2015).

As several excellent reviews on the development of recombinant $\mathrm{LAB}$ as a vaccine candidate against various infectious diseases have been published recently (Wyszyńska et al. 2015; Szatraj et al. 2017; de Castro et al. 2018; LeCureux and Dean 2018), and as they have covered the generation of recombinant $L A B$ vaccine strains, the effects of antigen localization or LAB strains used on their immunogenicity, and the securing of safety in clinical use, here we will discuss the following five issues that have been rarely studied or discussed to date in LAB vaccine research: (1) immune responses other than antibody production, (2) persistence of LAB vaccine immunity, (3) limitations of published comparative evaluation of $\mathrm{LAB}$ vaccines, (4) strategies for increasing the immunogenicity of $\mathrm{LAB}$ vaccines, and (5) the effects of microbiota on the efficacy of $L A B$ vaccines.

In Table 1 (for virus antigens) and Table 2 (for bacterial or others antigens), we listed the studies on LAB-based vaccine candidates that are discussed in this review or those worthy looking into, as they analyzed various endpoints for evaluation of LAB vaccine efficacy, including T cell and/or dendritic cell (DC) activation, neutralizing activities, and protective effects against challenge of pathogens, on top of the antibody response which is the only endpoint described in most publications. We hope that this article stimulates informative discussion on research issues related to $\mathrm{LAB}$ vaccine development, as well as practical ideas for planning future $\mathrm{LAB}$ vaccine experiments.

\section{Issues related to the development of LAB vaccines}

\section{Immune responses other than antibody production}

The majority of the published works on the development of LAB vaccines has focused on whether administration of each recombinant $\mathrm{LAB}$ strain can induce antigen-specific antibody responses, not only because measurement of antibody titers is the simplest way to evaluate immune responses, but also because antibodies play a critical role in many approved vaccines, such as influenza, hepatitis, and unconjugated pneumococcal vaccines. As a result, there is a growing number of reports showing that the mucosal administration of recombinant LAB-expressing antigens can induce antigen-specific mucosal and systemic antibody production. However, for evaluation of vaccine efficacies, it is not always enough to only confirm the increase in antibody titer. Indeed, even if the specific antibody titer rises, such indications are often insufficient for protection against infection (Perez et al. 2005; Sim et al. 2008; Marelli et al. 2011; Berlec et al. 2013). In other words, antibody levels measured by ELISA do not always correlate with the level of protection. Therefore, consideration of the contribution of antibodies to the protective function requires the differentiation of functional antibodies from non-functional, binding antibodies. Measuring of functional antibodies is performed by neutralization assay, opsonophagocytic killing assay, and complement fixation test. In addition to the measurement of the binding and functional antibody titers, confirmation of the protective effect of the vaccine in challenge experiments is important for evaluating the effectiveness of the vaccine. Recently, several reports have suggested that not only $\mathrm{CD} 4^{+}$but also $\mathrm{CD} 8^{+} \mathrm{T}$ cell immune responses are induced in mice immunized with $L$. lactis vaccines (Kawana et al. 2014; Chamcha et al. 2015; Zhao et al. 2017). However, these studies did not directly demonstrate a role of the $\mathrm{CD} 8^{+}$responses. Based on antibody-dependent depletion experiments, Sebbane and his colleagues found that $\mathrm{CD}^{+} \mathrm{T}$ cells had a moderate role in the vaccine effect of L. lactis-secreting LcrV, known as an essential component of the type III secretion system of Yersinia pseudotuberculosis (Y. pseudotuberculosis) and as a potential vaccine candidate, although activated $\mathrm{CD} 4^{+}$cells were necessary for vaccineinduced protection (Daniel et al. 2016). It would be critical to study whether immune responses other than antibody responses induced by the LAB vaccination, such as cellmediated immunity, are responsible for the protection.

In recent years, basic research on deciphering the cellular and humoral immune responses has advanced our knowledge of immunology. Along with these advances, the role of cell-mediated immunity is being increasingly recognized as important not just for the prevention of viral infections but also for the prevention of bacterial infections, differentiation of memory cells, and maintenance of antibody production. Indeed, vaccines licensed in the recent years and those close to licensure measure cellular immunology as a part of their endpoints in clinical trials, as recommended by both the WHO and EMA guidelines (World Health Organization 2015; European Medicines Agency 2018). However, the study of cellular immunity remains challenging as the methods used for its assessment are more complex than those for measuring humoral immunity. Therefore, selecting $\mathrm{T}$ cell readouts for measurement in pre-clinical vaccine studies to assess vaccine immunogenicity and efficacy requires careful consideration. Currently, in LAB vaccine studies, measurements of IgG subclasses, such as IgG1, IgG2a, and IgG2b, in ELISA are commonly used to assess the Th1/Th2 balance 


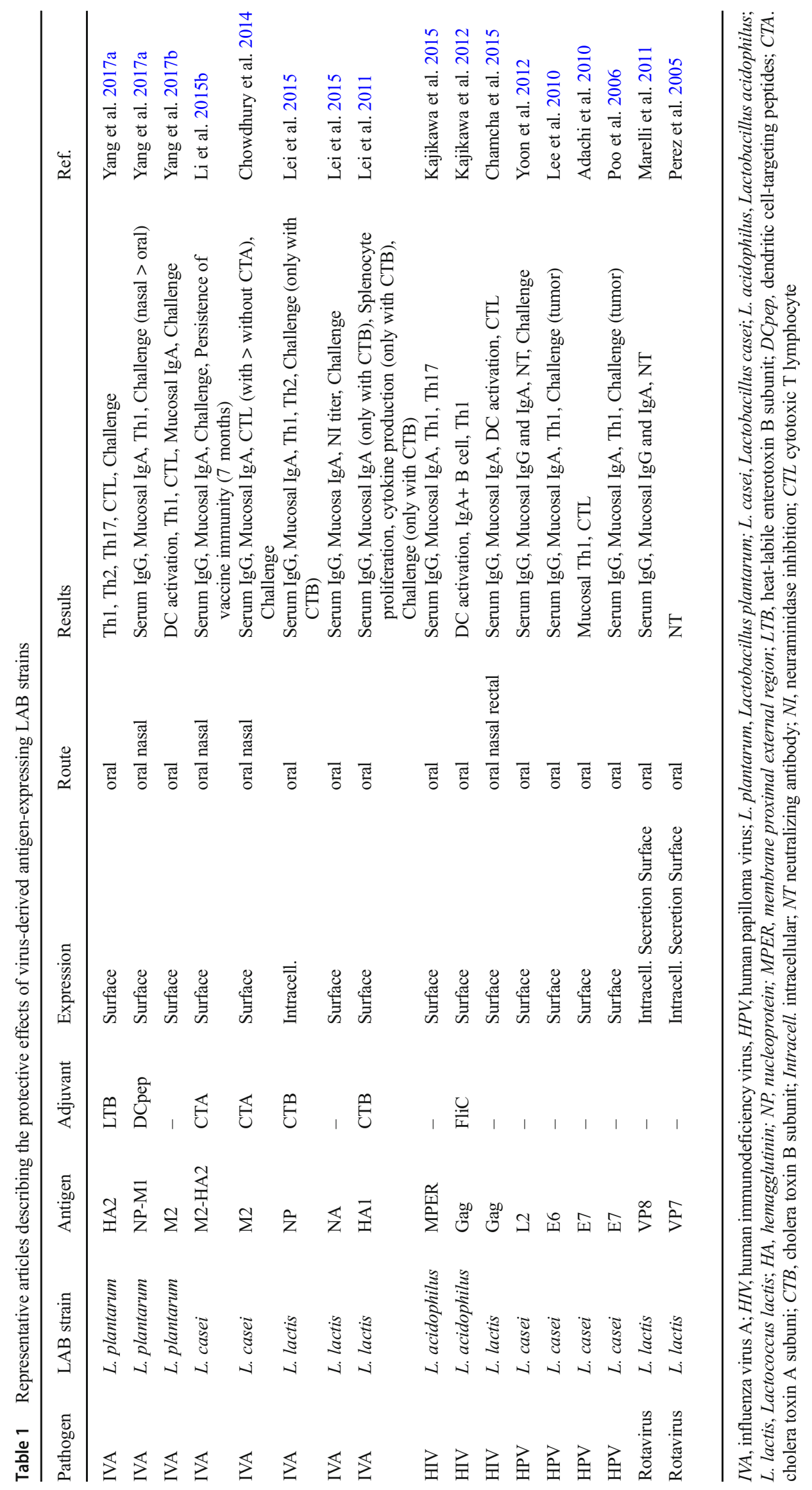




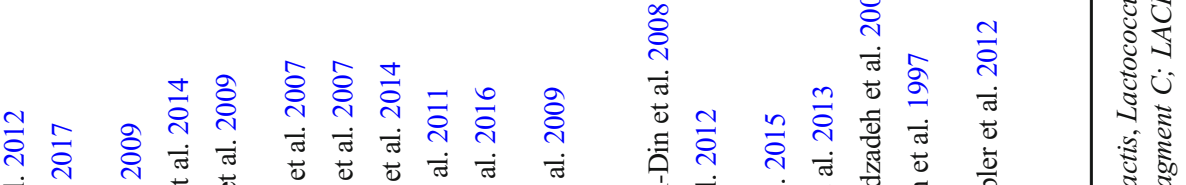

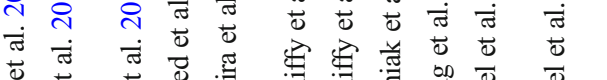

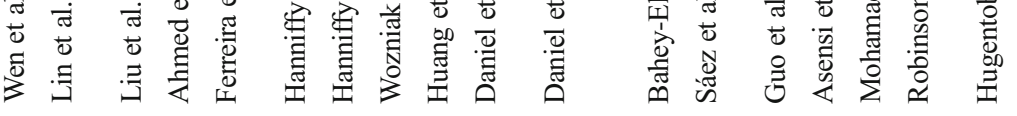

¿

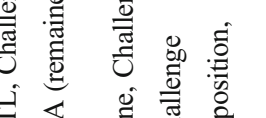

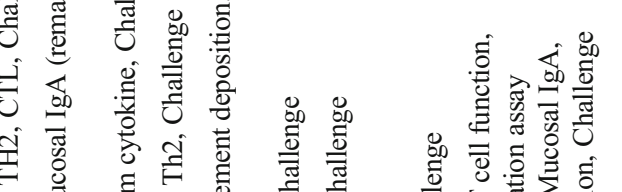

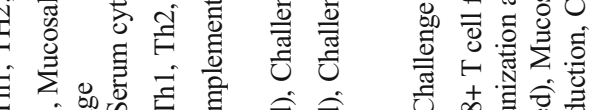

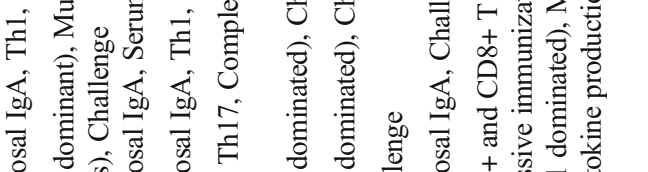

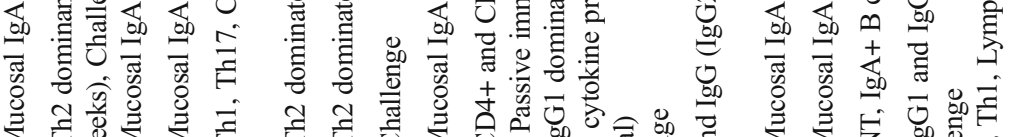

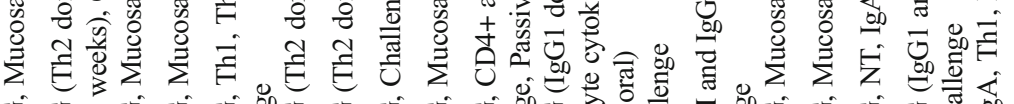

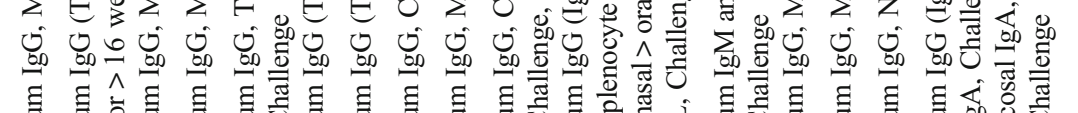

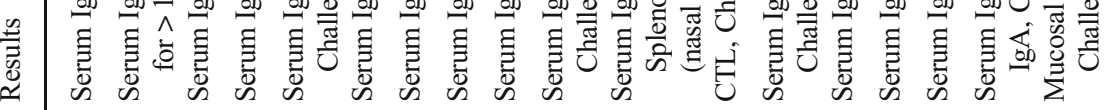

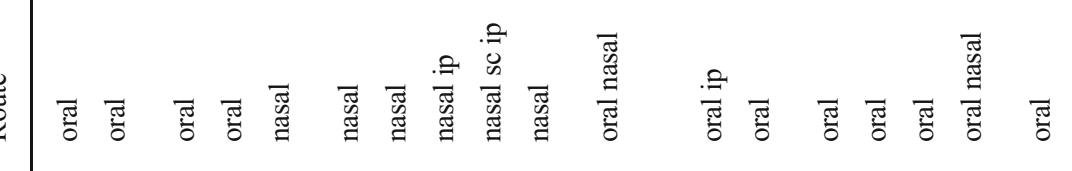

迹

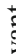

龸

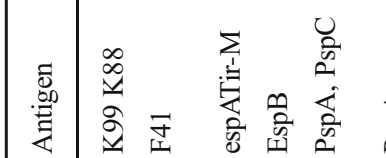

$\stackrel{3}{3}$

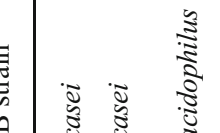

臂

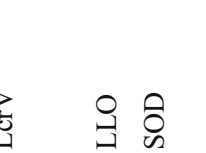

曼

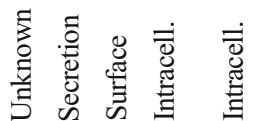

혼

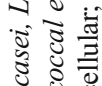

골ำ

疍

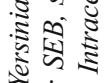

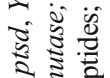

空 हू

تิ

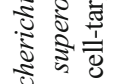

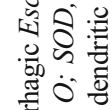

चे

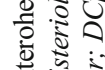

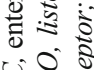

녹원

突 今

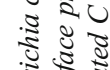

है

造

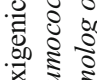

范 ․․․

चू क्ष

出恣言 
of vaccine immunity, as switching to each subclass is controlled under specific cytokine environments. In addition, measurement of IFN- $\gamma$ - or Th2 cytokines, such as IL-4, -producing $\mathrm{CD}^{+}$or $\mathrm{CD}^{+} \mathrm{T}$ cells in PBMCs (peripheral blood mononuclear cells) or in materials isolated from the systemic or mucosal lymphoid tissues (spleen, mesenteric lymph nodes, Peyer's patches, etc.) by flow cytometry or enzyme-linked immunospot (ELISpot) assay is used to evaluate helper $\mathrm{T}$ cell types and cell-mediated immunity. Moreover, methods based on the detection of markers of the degranulation of effector cytotoxic $\mathrm{T}$ lymphocytes (CTLs), such as perforin and granzyme B, or markers of apoptosis or necrosis of target cells are used for the measurement of CTL function (BermúdezHumarán et al. 2005; Adachi et al. 2010; Chamcha et al. 2015). These indicators are particularly important for the development of vaccines against intracellular bacteria and viruses. The type of immunity induced by LAB vaccine is influenced by the adjuvant effect of the LAB species, summarized in detail by Szatraj et al. (2017). LAB affect cytokine production from intestinal epithelial cells and immune cells and the produced cytokine milieus greatly depend on the LAB strain, resulting in the difference in adjuvant properties for the type of immunity (Th1, Th2, or Th1/Th2 mixed) induced. Thus, for LAB vaccine development, selection of LAB species/strains would be important for induction of the desired immune responses for protection from target pathogens. Or designing LAB to express a certain cytokine would help vaccine development suitable for the purposes as discussed later.

\section{Persistence of vaccine immunity}

In general, protective immunity induced by vaccination wanes with time. Insufficient protection due to waning vaccine immunity, known as secondary vaccine failure, has traditionally been more associated with inactivated, subunit, and toxoid vaccines (e.g., pertussis, diphtheria, and tetanus) than liveattenuated vaccines. However, even in tetanus, which is considered to have a relatively short duration of immunity, the half-life of the specific antibody is more than 10 years (Lewis et al. 2014). To date, the duration of the LAB vaccine antibody response has been examined at most up to only a few months. Daniel et al. (2016) reported that in mice orally administrated with L. lactis-secreting LcrV, the antigen-specific serum antibody titer was maintained at 9 months after the first vaccine administration. However, protective immunity against $Y$. pseudotuberculosis intravenous challenge conferred by L. lactis-secreting LcrV decreased slightly over time. To understand the persistency of serum and mucosal antibody responses induced by priming with the oral administration of L. lactis-expressing HIV-1 Gag-p24 (LL-Gag) followed by boosting with the intramuscular administration of recombinant modified vaccinia Ankara (MVA) expressing Gag, Chamcha et al. (2015) tracked Gag-specific IgG in serum and $\operatorname{IgA}$ in feces over time. They observed measurable responses until 24 weeks after the MVA boost, demonstrating that LL-Gag/MVA vaccine induces relatively persistent antibody responses in the serum and intestinal secretions. Sim et al. (2008) reported that the serum antibody responses induced by the oral or nasal administration of L. lactis-expressing a domain III of E protein (EDIII), which is a major envelope protein of dengue virus and is known as a protective antigen, was sustained for at least 69 days after the last vaccine boost. Li et al. (2015b) reported that immunization of mice with $L$. casei-expressing a fusion protein of influenza virus matrix protein 2 (M2), a well-conserved envelop ion channel protein, hemagglutinin II (HA2) and cholera toxin A (CT-A) subunit, a strong mucosal adjuvant without toxicity, on its surface. Inclusion of CT-A led to the significantly improved antibody levels and protection and allowed to maintain the antibody and protection levels for more than 7 months after immunization. All mentioned studies here suggest that antigen type and immunization regimen, including the route and number and interval of doses, for individual vaccines may affect the duration of persistence. Therefore, it is important to determine the conditions suitable for literally long-lasting protective efficacy by follow-up studies on the immunity levels for a sufficiently long term.

Research on subsets of memory cells and their functions has advanced recently (Todryk 2018). As the induction of memory cells is critical for long-lasting vaccine immunity, we should investigate whether LAB vaccines can induce long-lived memory $\mathrm{T}$ and $\mathrm{B}$ cells in sufficient numbers and with the correct phenotype capable of clearing pathogens that eventually infect the host at a late time point. Recent studies in mice have suggested that memory $\mathrm{T}$ cells that accumulate in tissues, termed tissue-resident memory $\mathrm{T}\left(\mathrm{T}_{\mathrm{RM}}\right)$ cells, play a crucial role in maintaining long-term protective immunity to mucosal pathogens (Takamura 2018; Wilk and Mills 2018). However, the role of CD4 ${ }^{+} \mathrm{T}_{\mathrm{RM}}$ cells in protective immunity generated by $\mathrm{LAB}$ vaccines has not been investigated. Therefore, the detection and quantification of $\mathrm{CD}^{+} \mathrm{T}_{\mathrm{RM}}$ cells in tissues in immunized hosts are important for the evaluation LAB vaccine immunity.

\section{Limitations of published comparative evaluation of $L A B$ vaccines}

Most studies to date have focused on the development of immunogenic recombinant $\mathrm{LAB}$ strains, demonstrating that antigen-specific immunity can be induced by the mucosal administration of LAB vaccines (Wyszyńska et al. 2015). Comparative analyses using standard/reference vaccines play a vital role in the clarification of the toxicity, immunogenicity, and potency of a novel vaccine. However, few studies have 
compared the effectiveness/protective efficacy of LAB vaccines with existing or standard vaccines. Although limited examples used as the references to compare with $L A B$ vaccines include inactivated whole pathogen, virus-like particles, or antigen mixed with well-known adjuvant, most of such antigens have been used for induction of humoral immunity. Sim et al. (2008) utilized the intraperitoneal administration of heat-inactivated dengue virus particles as a reference to evaluate the efficacy of oral and nasal vaccination with $L$. lactisexpressing dengue virus EDIII. The binding and neutralizing titers of anti-EDIII IgG antibodies induced by the nasal or oral administration of EDIII-expressing L. lactis in BALB/c mice were generally lower than those elicited in mice immunized by intraperitoneal injection of the reference. Yoon et al. (2012) reported injection of the reference. Yoon et al. (2012) reported that oral administration of Lactobacillus casei-expressing human papillomavirus (HPV)-16 L2 capsid protein induced serum and vaginal IgG and IgA production, and that the neutralization titers of the serum or vaginal wash from immunized mice were at a level comparable to those from mice subcutaneously immunized with purified HPV-16 L1 virus-like particles. Recently, Wagachchi et al. (2018) compared oral vaccinations with recombinant $L$. lactis expressing a fusion protein of the M1 pilus of Streptococcus pyogenes and Ova324-339 peptide (LL-M1p-Ova) and with CT-B-adjuvanted OVA peptides. LL-M1p-Ova induced systemic and mucosal antibody responses at a level similar to that of the OVA peptides/CT-B. Although application of the toxin adjuvants to human vaccine use is limited due to their toxicity (Lycke 2012), the use of candidate antigens adjuvanted with these toxins can be a useful reference for the comparative evaluation of the efficacy of $\mathrm{LAB}$ vaccines for the same antigens at least in pre-clinical studies. As the published comparative evaluation of $L A B$ vaccines was dependent mainly on antibody titers, comparison based on protective efficacy is definitely required for future studies.

\section{Strategies for increasing the immunogenicity of LAB vaccines}

Many studies have reported that $\mathrm{LAB}$ vaccine can induce antigen-specific antibody responses, but antibody titers are often not very high and may be almost none. Therefore, enhancing immunogenicity of $\mathrm{LAB}$ vaccines, which is defined by the adjuvanticity of LAB and the immunogenicity of antigen, remains a challenging approach. Several studies have explored strategies for expressing adjuvants, such as cytokines, along with antigens to improve adjuvanticity of LAB. For example, Hugentobler et al. (2012) and Sáez et al. (2012) reported the effectiveness of IL-12 as an adjuvant, and it is possible to skew the immune response to the Th1-type by co-expressing IL-12 with antigens. In addition, there are reports that IL- 2 or IL- 6 can be used as an adjuvant (Steidler et al. 1998). The use of these cytokine adjuvants makes it possible not only to enhance vaccine immunogenicity but also to control the type of immune response (for example, Th1 or Th2) to that best suited to protection against the target pathogen infection.

Other approaches are focusing on improvement of the immunogenicity of antigens. For example, pathogen-associated molecular patterns (PAMPs), targeting molecules for M cells and dendritic cells (DCs), and toxins, fused with antigens. With regard to the application of PAMPs to adjuvants, Kajikawa and his colleagues reported a method of expressing FliC (a ligand of TLR5), a component of bacterial flagellin, as a fusion protein with the antigen (Kajikawa et al. 2012). The mucosal adjuvant function of FliC has also been reported in another mucosal vaccine system (Van Maele et al. 2014). We and other groups have reported that the immunogenicity of $\mathrm{LAB}$ vaccines can be improved by fusing the antigen with a molecule targeting $\mathrm{M}$ cells, a specialized cell for antigen uptake into the Peyer's patches (Li et al. 2015a; Liu et al. 2018; Takahashi et al. 2018). Methods for increasing immunogenicity by fusing the antigen with peptides targeting DCs have also been reported (Mohamadzadeh et al. 2009; Yang et al. 2017). As the toxicity of toxin adjuvants may spoil immune responses enhanced by fusing antigens with toxins (Lei et al. 2011; Chowdhury et al. 2014; Lei et al. 2015; Li et al. 2015b; Jiang et al. 2017), novel mucosal adjuvants, such as the one reported recently (Aoshi 2017), should be examined in the context of $\mathrm{LAB}$ vaccines.

\section{Impact of microbiota on vaccine efficacy}

Growing evidence suggests that a symbiotic relationship between animals and microbiota is critical for the maintenance of health, including not only the acquisition of nutrients but also the development of the host immune system (Suzuki and Nakajima 2014; Honda and Littman 2016; Belkaid and Harrison 2017). Based on the role of gut microbiota in the development of the immune system, it is logical to expect that the microbiota may influence the efficacy of vaccines, especially mucosal vaccines. Indeed, Kim et al. (2017) recently reviewed the relationship between microbiota and the efficacy of vaccines or mucosal adjuvants. There have been no reports on detailed studies of the effects of bacterial flora and LAB vaccines so far. Early studies have suggested that antigen expression levels and the intestinal persistence of $\mathrm{LAB}$ influence the efficacy of LAB vaccines (Grangette et al. 2001; Grangette et al. 2002). Microbiota are likely to affect the metabolism and colonization of the administered LAB, which may alter the effectiveness of $\mathrm{LAB}$ vaccines.

In addition to microbial sensing and activation of the innate immune system by host cells, recent studies have clearly shown the importance of bacterial metabolites, such as short-chain fatty acids, in the gut immune responses (Kim et al. 2017; Mariño et al. 2017; Sun et al. 2018). Although 
those studies indicated that acetic acid and butyric acid, among the various short chain fatty acids, affect the number and functions of effector and regulatory $\mathrm{T}$ cells, lactic acid and its metabolite lactate produced by LAB have been reported to enhance the host intestinal immune system by increasing the antigen up-take of CX3CR1 ${ }^{+}$cells (Morita et al. 2019). Alternatively, LAB may directly affect the microbiota as they have probiotic properties (Patel and Dupont 2015). Accordingly, it is possible that the mutual interaction between the administered LAB and microbiota modulate the host immune system, ultimately affecting the outcome of LAB-based vaccination.

Investigations of the relationship between microbiota and the efficacy of vaccines are at an initial stage, and the data accumulated so far are limited. Therefore, elucidation on the most effective microbiota composition in promoting the efficacy of LAB vaccines will afford important information toward the human application of $L A B$ vaccines.

\section{Conclusions and future perspectives}

Previous studies have shown that LAB are attractive and promising candidates as mucosal vaccine carriers. Research on $\mathrm{LAB}$ vaccines has been focused to date on whether antigen-specific immunity, particularly antibody responses, can be induced. Indeed, as most approved vaccines, especially subunit vaccines, work through the production of specific antibodies, it is natural to regard antibody production as one of the endpoints of LAB vaccine development. However, with the recent developments in immunology, microbiology, and vaccinology, more detailed analyses of various mechanisms (for example, the induction of cell-mediated immunity and memory cells) are required for the vaccine development and licensure. These components of the immune system are especially important in the development of vaccines against infections that could not be controlled by previous antibody-based vaccine systems. In addition, with the spread of nextgeneration sequencers, the analysis of the microbiota at the mucosal surface has been greatly advanced, and the relationship between microbiota and host immunity is becoming apparent. As mucosal immunity is considered to be particularly affected by bacterial flora, it is important to investigate the relationship between the efficacy of the mucosal vaccine systems, including the LAB vaccines, and the host bacterial flora. We believe that further understanding of the issues raised in this review is critical for the practical application of this vaccine system.

\section{Compliance with ethical standards}

Conflict of interest The authors declare that they have no conflicts of interest.
Ethical statements All animal procedures that we performed and described in this review were approved by the Animal Care and Use Committee of Gifu Pharmaceutical University. Materials obtained from human subjects were not used.

\section{References}

Adachi K, Kawana K, Yokoyama T, Fujii T, Tomio A, Miura S, Tomio K, Kojima S, Oda K, Sewaki T, Yasugi T, Kozuma S, Taketani Y (2010) Oral immunization with a Lactobacillus casei vaccine expressing human papillomavirus (HPV) type $16 \mathrm{E} 7$ is an effective strategy to induce mucosal cytotoxic lymphocytes against HPV16 E7. Vaccine 91:296307. https://doi.org/10.1016/j.vaccine.2010.02.005

Ahmed B, Loos M, Vanrompay D, Cox E (2014) Oral immunization with Lactococcus lactis-expressing EspB induces protective immune responses against Escherichia coli $\mathrm{O} 157: \mathrm{H} 7$ in a murine model of colonization. Vaccine 32(31):3909-3916

Aoshi T (2017) Modes of action for mucosal vaccine adjuvants. Viral Immunol. https://doi.org/10.1089/vim.2017.0026

Asensi GF, de Sales NFF, Dutra FF, Feijó DF, Bozza MT, Ulrich RG, Miyoshi A, de Morais K, Azevedo VA d C, Silva JT, Le Loir Y, Paschoalin VMF (2013) Oral immunization with Lactococcus lactis secreting attenuated recombinant staphylococcal enterotoxin B induces a protective immune response in a murine model. Microb Cell Factories 12(1):32

Bahey-El-Din M, Casey PG, Griffin BT, Gahan CGM (2008) Lactococcus lactis-expressing listeriolysin O (LLO) provides protection and specific CD8+ T cells against Listeria monocytogenes in the murine infection model. Vaccine 26(41):5304-5314

Belkaid Y, Harrison OJ (2017) Homeostatic immunity and the microbiota. Immunity 46:562-576. https://doi.org/10.1016/j.immuni.2017.04.008

Berlec A, Malovrh T, Zadravec P, Steyer A, Ravnikar M, Sabotič J, Poljšak-Prijatelj M, Štrukelj B (2013) Expression of a hepatitis a virus antigen in Lactococcus lactis and Escherichia coli and evaluation of its immunogenicity. Appl Microbiol Biotechnol 97:43334342. https://doi.org/10.1007/s00253-013-4722-3

Bermúdez-Humarán LG, Cortes-Perez NG, Lefèvre F, Guimarães V, Rabot S, Alcocer-Gonzalez JM, Gratadoux J-J, Rodriguez-Padilla C, Tamez-Guerra RS, Corthier G, Gruss A, Langella P (2005) A novel mucosal vaccine based on live Lactococci expressing E7 antigen and IL-12 induces systemic and mucosal immune responses and protects mice against human papillomavirus type 16-induced tumors. J Immunol 175:7297-7302

Chamcha V, Jones A, Quigley BR, Scott JR, Amara RR (2015) Oral immunization with a recombinant Lactococcus lactis-expressing HIV-1 antigen on group a Streptococcus pilus induces strong mucosal immunity in the gut. J Immunol 195:5025-5034. https://doi.org/ 10.4049/jimmunol.1501243

Chen K, Cerutti A (2010) Vaccination strategies to promote mucosal antibody responses. Immunity 33:479-491. https://doi.org/10. 1016/j.immuni.2010.09.013

Chowdhury MYE, Li R, Kim JH, Park ME, Kim TH, Pathinayake P, Weeratunga P, Song MK, Son HY, Hong SP, Sung MH, Lee JS, Kim CJ (2014) Mucosal vaccination with recombinant Lactobacillus casei-displayed CTA1-conjugated consensus matrix protein-2 (sM2) induces broad protection against divergent influenza subtypes in BALB/c mice. PLoS One 9:e94051. https://doi.org/ 10.1371/journal.pone.0094051

Corthésy B, Bioley G (2018) Lipid-based particles: versatile delivery systems for mucosal vaccination against infection. Front Immunol 9:431. https://doi.org/10.3389/fimmu.2018.00431

da Silva AJ, Zangirolami TC, Novo-Mansur MTM, de Campos Giordano R, Martins EAL (2014) Live bacterial vaccine vectors: an overview. 
Braz J Microbiol 45:1117-1129. https://doi.org/10.1590/S151783822014000400001

Daniel C, Sebbane F, Poiret S, Goudercourt D, Dewulf J, Mullet C, Simonet M, Pot B (2009) Protection against Yersinia pseudotuberculosis infection conferred by a Lactococcus lactis mucosal delivery vector secreting LcrV. Vaccine 27(8):1141-1144

Daniel C, Titecat M, Poiret S, Cayet D, Boutillier D, Simonet M, Sirard JC, Lemaitre N, Sebbane F (2016) Characterization of the protective immune response to Yersinia pseudotuberculosis infection in mice vaccinated with an LcrV-secreting strain of Lactococcus lactis. Vaccine 34: 5762-5767. https://doi.org/10.1016/j.vaccine.2016.09.060

de Castro CP, Drumond MM, Batista VL, Nunes A, Mancha-Agresti P, Azevedo V (2018) Vector development timeline for mucosal vaccination and treatment of disease using Lactococcus lactis and design approaches of next generation food grade plasmids. Front Microbiol 14:1805. https://doi.org/10.3389/fmicb.2018.01805

European Medicines Agency (2018) Guideline on clinical evaluation of vaccines. http://www.ema.europa.eu/docs/en GB/\%0Adocument library/Scientific_guideline/2018/04/WC500248095.pdf

Ferreira DM, Darrieux M, Silva DA, Leite LCC, Ferreira JMC, Ho PL, Miyaji EN, Oliveira MLS (2009) Characterization of protective mucosal and systemic immune responses elicited by Pneumococcal surface protein PspA and PspC nasal vaccines against a respiratory Pneumococcal challenge in mice. Clin Vaccine Immunol 16(5):636-645

Grangette C, Müller-Alouf H, Goudercourt D, Geoffroy MC, Turneer M, Mercenier A (2001) Mucosal immune responses and protection against tetanus toxin after intranasal immunization with recombinant Lactobacillus plantarum. Infect Immun 69:1547-1553. https://doi. org/10.1128/IAI.69.3.1547-1553.2001

Grangette C, Müller-Alouf H, Geoffroy MC, Goudercourt D, Turneer M, Mercenier A (2002) Protection against tetanus toxin after intragastric administration of two recombinant lactic acid bacteria: impact of strain viability and in vivo persistence. Vaccine 20:3304 3309. https://doi.org/10.1016/S0264-410X(02)00301-8

Guo S, Yan W, McDonough SP, Lin N, Wu KJ, He H, Xiang H, Yang M, Moreira MAS, Chang Y-F (2015) The recombinant Lactococcus lactis oral vaccine induces protection against $C$. difficile spore challenge in a mouse model. Vaccine 33(13):1586-1595

Hanniffy SB, Carter AT, Hitchin E, Wells JM (2007) Mucosal delivery of a pneumococcal vaccine using affords protection against respiratory infection. J Infect Dis 195(2): 185-193

Honda K, Littman DR (2016) The microbiota in adaptive immune homeostasis and disease. Nature 535:75-84. https://doi.org/10.1038/ nature 18848

Huang Y-S, Fisher M, Nasrawi Z, Eichenbaum Z (2011) Defense from the group A Streptococcus by active and passive vaccination with the Streptococcal hemoprotein receptor. J Infect Dis 203(11):1595-1601

Hugentobler F, Di Roberto RB, Gillard J, Cousineau B (2012) Oral immunization using live Lactococcus lactis co-expressing LACK and IL-12 protects BALB/c mice against Leishmania major infection. Vaccine 30(39):5726-5732

Jiang Y, Yang G, Wang Q, Wang Z, Yang W, Gu W, Shi C, Wang J, Huang H, Wang C (2017) Molecular mechanisms underlying protection against $\mathrm{H} 9 \mathrm{~N} 2$ influenza virus challenge in mice by recombinant Lactobacillus plantarum with surface displayed HA2-LTB. J Biotechnol 259:6-14. https://doi.org/10.1016/j.jbiotec.2017.08.011

Kajikawa A, Zhang L, Long J, Nordone S, Stoeker L, LaVoy A, Bumgardner S, Klaenhammer T, Dean G (2012) Construction and immunological evaluation of dual cell surface display of HIV-1 gag and Salmonella enterica serovar typhimurium FliC in Lactobacillus acidophilus for vaccine delivery. Clin Vaccine Immunol 19:13741381. https://doi.org/10.1128/CVI.00049-12

Kajikawa A, Zhang L, LaVoy A, Bumgardner S, Klaenhammer TR, Dean GA, Ho PL (2015) Mucosal immunogenicity of genetically modified Lactobacillus acidophilus expressing an HIV-1 epitope within the surface layer protein. PLOS ONE 10(10):e014171
Kawana K, Adachi K, Kojima S, Taguchi A, Tomio K, Yamashita A, Nishida H, Nagasaka K, Arimoto T, Yokoyama T, Wada-Hiraike O, Oda K, Sewaki T, Osuga Y, Fujii T (2014) Oral vaccination against HPV E7 for treatment of cervical intraepithelial neoplasia grade 3 (CIN3) elicits E7-specific mucosal immunity in the cervix of CIN3 patients. Vaccine 32:6233-6239. https://doi.org/10.1016/j.vaccine. 2014.09.020

Kim S-H, Cho B-H, Kiyono H, Jang Y-S (2017) Microbiota-derived butyrate suppresses group 3 innate lymphoid cells in terminal ileal Peyer's patches. Sci Rep 7(1):3980. https://doi.org/10.1038/s41598017-02729-6

LeCureux JS, Dean GA (2018) Lactobacillus mucosal vaccine vectors: immune responses against bacterial and viral antigens. mSphere 3: e00061-e00018. https://doi.org/10.1128/mSphere.00061-18

Lee T-Y, Kim Y-H, Lee K-S, Kim J-K, Lee I-H, Yang J-M, Sung M-H, Park J-S, Poo H (2010) Human papillomavirus type 16 E6-specific antitumor immunity is induced by oral administration of HPV16 E6expressing Lactobacillus casei in C57BL/6 mice. Cancer Immunol Immunother 59(11):1727-1737

Lei H, Sheng Z, Ding Q, Chen J, Wei X, Lam DMK, Xu Y (2011) Evaluation of oral immunization with recombinant avian influenza virus HA1 displayed on the Lactococcus lactis surface and combined with the mucosal adjuvant cholera toxin subunit B. Clin Vaccine Immunol 18:1046-1051. https://doi.org/10.1128/CVI.00050-11

Lei H, Peng X, Zhao D, Ouyang J, Jiao H, Shu H, Ge X (2015) Lactococcus lactis displayed neuraminidase confers cross protective immunity against influenza A viruses in mice. Virology 476:189-195

Lewis GK, DeVico AL, Gallo RC (2014) Antibody persistence and T-cell balance: two key factors confronting HIV vaccine development. Proc Natl Acad Sci 111:15614-15621. https://doi.org/10.1073/pnas. 1413550111

Li HS, Piao DC, Jiang T, Bok JD, Cho CS, Lee YS, Kang SK, Choi YJ (2015a) Recombinant interleukin 6 with M cell-targeting moiety produced in Lactococcus lactis IL1403 as a potent mucosal adjuvant for peroral immunization. Vaccine 33:1959-1967. https://doi.org/ 10.1016/j.vaccine.2015.02.061

Li R, Chowdhury MYE, Kim JH, Kim TH, Pathinayake P, Koo WS, Park ME, Yoon JE, Roh JB, Hong SP, Sung MH, Lee JS, Kim CJ (2015b) Mucosally administered Lactobacillus surface-displayed influenza antigens (sM2 and HA2) with cholera toxin subunit A1 (CTA1) induce broadly protective immune responses against divergent influenza subtypes. Vet Microbiol 179:250-263. https://doi.org/10. 1016/j.vetmic.2015.07.020

Lin IYC, Van TTH, Smooker PM (2015) Live-attenuated bacterial vectors: tools for vaccine and therapeutic agent delivery. Vaccines 3: 940-972. https://doi.org/10.3390/vaccines3040940

Lin R, Zhang Y, Long B, Li Y, Wu Y, Duan S, Zhu B, Wu X, Fan H (2017) Oral immunization with recombinant Lactobacillus acidophilus expressing espA-Tir-M confers protection against Enterohemorrhagic Escherichia coli O157:H7 Challenge in Mice. Front Microbiol 8:417. https://doi.org/10.3389/fmicb.2017.00417

Liu J-K, Hou X-L, Wei C-H, Yu L-Y, He X-J, Wang G-H, Lee J-S, Kim C-J (2009) Induction of Immune Responses in Mice after Oral Immunization with Recombinant Lactobacillus casei Strains Expressing Enterotoxigenic Escherichia coli F41 Fimbrial Protein. Appl Environ Microbiol 75(13):4491-4497

Liu L, Zhang W, Song Y, Wang W, Zhang Y, Wang T, Li K, Pan Q, Qi X, Gao Y, Gao L, Liu C, Zhang Y, Wang Y, He G, Wang X, Cui H (2018) Recombinant Lactococcus lactis co-expressing OmpH of an $\mathrm{M}$ cell-targeting ligand and IBDV-VP2 protein provide immunological protection in chickens. Vaccine 36:729-735. https://doi.org/10. 1016/j.vaccine.2017.12.027

Lycke N (2012) Recent progress in mucosal vaccine development: Potential and limitations. Nat Rev Immunol 12:592-605. https:// doi.org/10.1038/nri3251 
Marelli B, Perez AR, Banchio C, de Mendoza D, Magni C (2011) Oral immunization with live Lactococcus lactis expressing rotavirus VP8* subunit induces specific immune response in mice. J Virol Methods 175:28-37. https://doi.org/10.1016/j.jviromet.2011.04.011

Mariño E, Richards JL, McLeod KH, Stanley D, Yap YA, Knight J, McKenzie C, Kranich J, Oliveira AC, Rossello FJ, Krishnamurthy B, Nefzger CM, Macia L, Thorburn A, Baxter AG, Morahan G, Wong LH, Polo JM, Moore RJ, Lockett TJ, Clarke JM, Topping DL, Harrison LC, Mackay CR (2017) Gut microbial metabolites limit the frequency of autoimmune $\mathrm{T}$ cells and protect against type 1 diabetes. Nat Immunol 18:552-562. https://doi.org/10.1038/ni.3713

Mestecky J, Russell MW, Elson CO (2007) Perspectives on Mucosal Vaccines: Is Mucosal Tolerance a Barrier? J Immunol 179:56335638. https://doi.org/10.4049/jimmunol.179.9.5633

Mohamadzadeh M, Duong T, Sandwick SJ, Hoover T, Klaenhammer TR (2009) Dendritic cell targeting of Bacillus anthracis protective antigen expressed by Lactobacillus acidophilus protects mice from lethal challenge. Proc Natl Acad Sci 106:4331-4336. https://doi.org/ 10.1073/pnas.0900029106

Morita N, Umemoto E, Fujita S, Hayashi A, Kikuta J, Kimura I, Haneda T, Imai T, Inoue A, Mimuro H, Maeda Y, Kayama H, Okumura R, Aoki J, Okada N, Kida T, Ishii M, Nabeshima R, Takeda K (2019) GPR31-dependent dendrite protrusion of intestinal CX3CR1+ cells by bacterial metabolites. Nature 566(7742):110-114. https://doi.org/ 10.1038/s41586-019-0884-1

Patel R, Dupont HL (2015) New approaches for bacteriotherapy: prebiotics, new-generation probiotics, and synbiotics. Clin Infect Dis 60: S108-S121. https://doi.org/10.1093/cid/civ177

Perez CA, Eichwald C, Burrone O, De Mendoza D (2005) Rotavirus vp7 antigen produced by Lactococcus lactis induces neutralizing antibodies in mice. J Appl Microbiol 99:1158-1164. https://doi.org/10. 1111/j.1365-2672.2005.02709.x

Poo H, Pyo H-M, Lee T-Y, Yoon S-W, Lee J-S, Kim C-J, Sung M-H, Lee S-H (2006) Oral administration of human papillomavirus type 16 E7 displayed on Lactobacillus casei induces E7-specific antitumor effects in C57/BL6 mice. Int J Cancer 119(7):1702-1709

Robinson K, Chamberlain LM, Schofield KM, Wells JM, Le Page RWF (1997) Oral vaccination of mice against tetanus with recombinant lactococcus lactis. Nat Biotechnol 15:653-7. https://doi.org/10. 1038/nbt0797-653

Sáez D, Fernández P, Rivera A, Andrews E, Oñate A (2012) Oral immunization of mice with recombinant Lactococcus lactis expressing $\mathrm{Cu}, \mathrm{Zn}$ superoxide dismutase of Brucella abortus triggers protective immunity. Vaccine 30(7):1283-1290

Schwendener RA (2014) Liposomes as vaccine delivery systems: a review of the recent advances. Ther Adv Vaccines 2:159-182. https:// doi.org/10.1177/2051013614541440

Sim ACN, Lin W, Tan GKX, Sim MST, Chow VTK, Alonso S (2008) Induction of neutralizing antibodies against dengue virus type 2 upon mucosal administration of a recombinant Lactococcus lactis strain expressing envelope domain III antigen. Vaccine 26:11451154. https://doi.org/10.1016/j.vaccine.2007.12.047

Steidler L, Robinson K, Chamberlain L, Schofield KM, Remaut E, Le Page RWF, Wells JM (1998) Mucosal delivery of murine interleukin-2 (IL-2) and IL-6 by recombinant of Lactococcus lactis coexpressing antigen and cytokine. Infect Immun 66:3183-3189

Sun M, Wu W, Chen L, Yang W, Huang X, Ma C, Chen F, Xiao Y, Zhao Y, Ma C, Yao S, Carpio VH, Dann SM, Zhao Q, Liu Z, Cong Y (2018) Microbiota-derived short-chain fatty acids promote Th1 cell IL-10 production to maintain intestinal homeostasis. Nat Commun 9:3555. https://doi.org/10.1038/s41467-018-05901-2

Suzuki K, Nakajima A (2014) New aspects of IgA synthesis in the gut. Int Immunol 26:489-494. https://doi.org/10.1093/intimm/dxu059

Szatraj K, Szczepankowska AK, Chmielewska-Jeznach M (2017) Lactic acid bacteria - promising vaccine vectors: possibilities, limitations, doubts. J Appl Microbiol 123:325-339. https://doi.org/10.1111/jam.13446
Takahashi K, Yano A, Watanabe S, Langella P, Bermúdez-Humarán LG, Inoue N (2018) M-cell targeting strategy enhances systemic and mucosal immune responses induced by oral administration of nuclease-producing $L$. lactis. Appl Microbiol Biotechnol 102: 10703-10711. https://doi.org/10.1007/s00253-018-9427-1

Takamura S (2018) Niches for the long-term maintenance of tissueresident memory $\mathrm{T}$ cells. Front Immunol 9:1214. https://doi.org/ 10.3389/fimmu.2018.01214

Todryk SM (2018) T cell memory to vaccination. Vaccines 6:84. https:// doi.org/10.3390/vaccines6040084

Van Maele L, Fougeron D, Janot L, Didierlaurent A, Cayet D, Tabareau J, Rumbo M, Corvo-Chamaillard S, Boulenouar S, Jeffs S, Vande WL, Lamkanfi M, Lemoine Y, Erard F, Hot D, Hussell T, Ryffel B, Benecke AG, Sirard JC (2014) Airway structural cells regulate TLR5-mediated mucosal adjuvant activity. Mucosal Immunol 7: 489-500. https://doi.org/10.1038/mi.2013.66

Wagachchi D, Tsai JYC, Chalmers C, Blanchett S, Loh JMS, Proft T (2018) PilVax - a novel peptide delivery platform for the development of mucosal vaccines. Sci Rep 8:1-12. https://doi.org/10.1038/ s41598-018-20863-7

Wen L-J, Hou X-L, Wang G-H, Yu L-Y, Wei X-M, Liu J-K, Liu Q, Wei C-H (2012) Immunization with recombinant Lactobacillus casei strains producing K99, K88 fimbrial protein protects mice against enterotoxigenic Escherichia coli. Vaccine 30(22):3339-3349

Wilk MM, Mills KHG (2018) CD4 TRM cells following infection and immunization: implications for more effective vaccine design. Front Immunol 9:1860. https://doi.org/10.3389/fimmu.2018.01860

World Health Organization (2015) Guidelines on clinical evaluation of vaccines: regulatory expectations. WHO Tech Rep 35-102. https://www. who.int/biologicals/Clinical_guidelines_revised_IK_29_Oct 2015.pdf

Wozniak A, García P, Geoffroy EA, Aguirre DB, González SA, Sarno VA, Dale JB, Salazar-Echegarai FJ, Vera A, Bueno SM, Kalergis AM, Staats HF (2014) A novel live vector group A Streptococcal Type 9 vaccine delivered intranasally protects mice against challenge infection with Type 9 Group A Streptococci. Clin Vaccine Immunol 21(9):1343-1349

Wyszyńska A, Kobierecka P, Bardowski J, Jagusztyn-Krynicka EK (2015) Lactic acid bacteria-20 years exploring their potential as live vectors for mucosal vaccination. Appl Microbiol Biotechnol 99: 2967-2977. https://doi.org/10.1007/s00253-015-6498-0

Yang WT, Yang GL, Shi SH, Liu YY, Huang HB, Jiang YL, Wang JZ, Shi CW, Jing YB, Wang CF (2017a) Protection of chickens against H9N2 avian influenza virus challenge with recombinant Lactobacillus plantarum expressing conserved antigens. Appl Microbiol Biotechnol 101:4593-4603. https://doi.org/10.1007/s00253-017-8230-8

Yang W-T, Yang G-L, Wang Q, Huang H-B, Jiang Y-L, Shi C-W, Wang J-Z, Huang K-Y, Jin Y-B, Wang C-F (2017b) Protective efficacy of Fc targeting conserved influenza virus $\mathrm{M} 2 \mathrm{e}$ antigen expressed by Lactobacillus plantarum. Antiviral Res 138:9-21. https://doi.org/10. 1016/j.antiviral.2016.11.025

Yoon S, Lee T, Kim S, Lee I, Sung M, Park J, Poo H (2012) Oral administration of HPV-16 L2 displayed on Lactobacillus casei induces systematic and mucosal cross-neutralizing effects in Balb/c mice. Vaccine 30: 3286-3294. https://doi.org/10.1016/j.vaccine.2012.03.009

Zhao L, Guo Z, liu J, Wang Z, Wang R, Li Y, Wang L, Xu Y, Tang L, Qiao $X$ (2017) Recombinant Lactobacillus casei expressing Clostridium perfringens toxoids $\alpha, \beta 2, \varepsilon$ and $\beta 1$ gives protection against Clostridium perfringens in rabbits. Vaccine 35:4010-4021. https:// doi.org/10.1016/j.vaccine.2017.05.076

Publisher's note Springer Nature remains neutral with regard to jurisdictional claims in published maps and institutional affiliations. 